\title{
INTEGRAÇÃO ENTRE ATIVIDADES COMPUTACIONAIS E EXPERIMENTAIS COMO RECURSO INSTRUCIONAL NO ENSINO DE ELETROMAGNETISMO EM FÍSICA GERAL*
}

\author{
Integration between computational \\ and experimental activities as instructional resources \\ in teaching electromagnetism in General Physics
}

\author{
Pedro Fernando Teixeira Dorneles ${ }^{1}$. Ives Solano Araujo ${ }^{2}$. \\ Eliane Angela Veit ${ }^{3}$
}

\begin{abstract}
Resumo: Investigam-se formas de integração entre atividades computacionais e experimentais de modo a torná-las complementares, auxiliando os alunos a atingirem uma aprendizagem significativa de conceitos de Física e compreenderem algumas ideias sobre modelos científicos. A proposta didática, fundamentada: na teoria de Ausubel sobre aprendizagem significativa, na visão epistemológica de Bunge sobre modelos teóricos, e na teoria sociointeracionista de Vygotsky, foi aplicada a uma turma de licenciatura em Física da UFRGS, abrangendo todo o conteúdo de Eletromagnetismo em nível de Física Geral. Os resultados mostram que a integração proposta pode proporcionar aos alunos uma visão epistemológica mais adequada sobre o papel dos modelos teóricos em Física e das atividades computacionais e experimentais nos processos de aprendizagem, promovendo a interatividade e seu engajamento no próprio aprendizado, e transformando a sala de aula em um ambiente propício para uma aprendizagem significativa.

Palavras-chave: Atividades experimentais. Atividades computacionais. Eletromagnetismo. Ensino de física. Ensino Superior. Didática.

Abstract: The purpose was to investigate ways to integrate computational and experimental activities to make them complementary, thus helping students to achieve meaningful learning of physics concepts and to understand some ideas about scientific models. We designed a didactical approach covering electromagnetism topics at the level of General Physics based on Ausubel's meaningful learning theory, Bunge's epistemological view about scientific models and science development and Vygotsky's socialinteraction theory. This didactical approach was applied to a class of undergraduate physics students. The results show that the integration of these two kinds of activities can provide the students a more appropriate epistemological perspective of the roles of theoretical models in Physics and experimental and computational activities in the learning processes. This encourages interactivity and engagement of the students with their own learning, transforming the classroom into an environment suitable for the meaningful learning of physical concepts of electromagnetism.
\end{abstract}

Keywords: Computer activities. Experimental activities. Electromagnetism. Physics teaching. Higher education. Didactics.

\footnotetext{
* Trabalho parcialmente financiado pelo CNPq.

${ }^{1}$ Universidade Federal do Pampa, campus Bagé. Travessa 45, n 1650, Bairro Malafaia. Bagé, RS, Brasil. 96.413170.pedrodorneles@unipampa.edu.br

${ }^{2}$ Instituto de Física, Universidade Federal do Rio Grande do Sul (UFRGS). Bolsista da Capes.

${ }^{3}$ Instituto de Física, UFRGS.
} 
Dorneles, P. F. T.; Araujo, I. S.; Veit, E. A.

\section{Introdução}

É praticamente consensual entre professores de Física que o uso de experimentos didáticos é um componente indispensável no ensino da disciplina, porém muitos deles não são capazes de especificar claramente o que se espera do uso de atividades experimentais (AE) e confessam que pouco as usam em suas aulas. Vários trabalhos (HODSON, 1994; GIL-PÉREZ et al., 1999; RONEN; ELIAHU, 2000; BORGES, 2002; ZACHARIA, 2007) alertam que muitas das atividades propostas pelos docentes em aulas experimentais não privilegiam a interatividade e apresentam um distanciamento entre teoria e prática. No presente trabalho apresentamos os resultados de uma abordagem didática que tem como objetivo propiciar um vínculo entre teoria e experimento a partir da integração entre $\mathrm{AE}$ e atividades computacionais (AC), com base na interação entre domínios teóricos e procedimentos experimentais.

AE e AC têm sido objeto de pesquisa na área de ensino de Física, e podem-se encontrar, na literatura, estudos gerais que apresentam uma reflexão sobre os fatores positivos e negativos de sua implementação em sala de aula. Por exemplo, Hodson (1994) questiona uma série de argumentos usualmente apresentados na literatura em favor das atividades práticas, e Medeiros e Medeiros (2002) consideram que um dos principais fatores negativos das AC é o perigo da perda da referência objetiva, ocasionada pelo trabalho descontextualizado com simulações computacionais. Também têm sido propostas e investigadas metodologias didáticas que buscam integrar esses dois tipos de atividades, visando à maximização dos fatores positivos e à minimização dos negativos de ambos. Zacharia (2007), por exemplo, apresenta alguns fatores positivos das AC, como a manipulação mais fácil e rápida de variáveis comparada com a experimentação real e a rapidez na exibição de dados dinâmicos, que podem tornar o ensino de laboratório mais eficaz, propiciando melhores condições para que os alunos atinjam uma aprendizagem conceitual do que se tivessem trabalhado somente com experimentos. Localizamos, na literatura (DORNELES, 2010), somente três estudos sobre a integração entre atividades experimentais e computacionais no ensino de Eletromagnetismo no período de 1994 a 2009 (RONEN; ELIAHU, 2000; ZACHARIA, 2007; JAAKKOLA; NURMI, 2008). Dentre as investigações sobre essa integração em outras áreas da Física, destacamos os estudos de Zacharia e Anderson (2003) e de Hennessy, Deaney e Ruthuven (2006) na área de Mecânica, e os estudos de Zacharia e Constantinou (2008) e de Zacharia, Olympiou e Papaevripidou (2008) em Termodinâmica.

Ronen e Eliahu (2000) investigaram o papel de uma simulação computacional como recurso didático para auxiliar os alunos no aprendizado da física envolvida em circuitos elétricos simples, partindo do princípio de que a simulação pode diminuir o distanciamento entre teoria e realidade. Seus resultados indicam que a realização de atividades no computador, além de motivar e aumentar a confiança dos alunos no trabalho que estão desenvolvendo, constitui uma excelente opção para auxiliá-los a compreender a relação entre modelos teóricos, representações formais e a realidade. Zacharia (2007) averiguou o entendimento conceitual de alunos que utilizaram AC como complemento às AE no ensino de circuitos elétricos. Os resultados encontrados mostram que o uso integrado propiciou uma melhor compreensão conceitual dos alunos comparado com a dos que trabalharam somente com atividades experimentais. Sobre esse resultado, Zacharia (2007) apresenta o comentário de que as AC: i) tornaram os fenômenos mais visíveis para os alunos; ii) permitiram aos alunos a manipulação mais fácil e 
rápida de variáveis, comparada com a experimentação real; iii) propiciaram um feedback, especialmente sobre os erros cometidos pelos alunos durante todo o processo de construção dos circuitos. Jaakkola e Nurmi (2008) tiveram como objetivo avaliar se há vantagens em combinar $\mathrm{AC}$ e AE, ou se essas atividades devem ser usadas separadamente no ensino de circuitos elétricos. Os resultados mostram que houve diferenças estatisticamente significativas a favor dos alunos que trabalharam com AC e AE integradas em relação ao desempenho de alunos que trabalharam somente com AC ou AE. Dentro do mesmo tema, Finkelstein et al. (2005) investigaram a possibilidade de substituir o ensino de laboratório por simulações computacionais no ensino de circuitos elétricos simples. O estudo envolveu dois grupos de alunos: um deles usou equipamento de laboratório e o outro usou simulações computacionais. Os resultados mostraram que os alunos que usaram simulações computacionais no lugar de equipamentos de laboratório tiveram melhor desempenho na resolução de questões conceituais sobre circuitos simples e, surpreendentemente, desenvolveram maior habilidade na manipulação de componentes reais.

\section{Objetivo do trabalho}

O objetivo geral deste estudo é investigar algumas formas de integração entre AC e AE de modo a torná-las complementares, se enquadrando nas linhas desenvolvidas por Ronen e Eliahu (2000), Jaakkola e Nurmi (2008) e Zacharia (2007), mas se diferenciando dessas pelo fato de utilizarmos explicitamente referenciais teóricos de aprendizagem e epistemológicos tanto para conceber, elaborar e aplicar o material instrucional, quanto na metodologia de avaliação dos dados coletados. Nos três artigos citados, não encontramos menções explícitas e significativas sobre o referencial teórico adotado.

Este trabalho faz parte de uma série de estudos (DORNELES; VEIT; MOREIRA, 2008, 2010; DORNELES; ARAUJO; VEIT, 2007; DORNELES; VEIT; ARAUJO, 2009), em que temos investigado a utilização de $\mathrm{AC}$ e $\mathrm{AE}$ no ensino de eletromagnetismo em física geral. Em todos os estudos, buscamos propiciar melhores condições para uma aprendizagem significativa, na acepção de Ausubel (2003), ou seja, consideramos que aprendizagem significativa é aquela em que o significado do novo conhecimento resulta da interação, de maneira não arbitrária e não literal, entre uma nova informação e um aspecto especificamente relevante da estrutura de conhecimento do aprendiz, à qual Ausubel (2003) define como subsunçor. Para isso, buscamos na literatura as principais dificuldades de aprendizagem dos alunos (DORNELES, 2010, p. 27-58), e procuramos conceber atividades instigantes capazes de motivar os alunos a relacionarem de forma significativa os conceitos físicos que pretendemos que aprendam com suas ideias e conceitos prévios.

O presente artigo envolve todo o conteúdo de eletromagnetismo em nível de física geral, e foi planejado a partir de proposições norteadoras geradas em estudo anterior (DORNELES; VEIT; ARAUJO, 2009), quais sejam, a integração entre AC e AE pode: 1) proporcionar aos alunos uma visão epistemológica sobre os papéis do laboratório, do computador e de modelos teóricos; 2) promover a interatividade e o engajamento dos alunos em seu próprio aprendizado, transformando a sala de aula em um ambiente propício para uma aprendizagem significativa dos conceitos físicos envolvidos. 
Pretendemos avaliar se nossa proposta de integração entre AC e AE propiciará, aos alunos, uma aprendizagem significativa dos conteúdos em questão e uma visão epistemológica sobre modelos teóricos, laboratório e uso do computador. Destacamos que nossa proposta além de estabelecer uma dinâmica de integração, envolve uma estratégia de ensino-aprendizagem, descrita a seguir.

\section{Metodologia}

\section{Embasamento teórico da abordagem didática}

Nossa proposta didática se caracteriza pela participação ativa dos alunos. Em relação à dinâmica das aulas, utilizamos o que denominamos de método colaborativo presencial ${ }^{4}$, ancorado nos princípios de diferenciação progressiva e reconciliação integrativa, propostos por Ausubel (2003), e na interação social proposta por Vygotsky (2003).

Segundo Ausubel (2003), as ideias mais gerais e mais inclusivas da matéria de ensino devem ser apresentadas no início do ensino para, somente então, serem progressivamente diferenciadas em seus pormenores e em suas especificidades. $\mathrm{O}$ autor baseia-se em duas hipóteses: i) é mais fácil para os seres humanos captarem aspectos diferenciados de um todo mais inclusivo previamente aprendido, do que chegar ao todo a partir de suas partes diferenciadas previamente aprendidas; ii) a organização do conteúdo de uma certa disciplina, na mente de um indivíduo, é uma estrutura hierárquica na qual as ideias mais inclusivas e gerais estão no topo e, progressivamente, incorporam proposições, conceitos e fatos menos inclusivos e mais diferenciados. Já a reconciliação integrativa é o princípio segundo o qual a instrução deve também explorar relações entre ideias, apontar similaridades e diferenças importantes e reconciliar discrepâncias reais ou aparentes, opondo-se à prática usual nos livros de texto, que consiste em separar ideias e tópicos em capítulos e em seções (MOREIRA, 2006, p. 36). Inspirados nessas ideias, apresentamos, na primeira parte de cada aula, uma exposição inicial, de aproximadamente $30 \mathrm{~min}$, sobre os conceitos físicos mais gerais envolvidos na matéria de ensino, para serem progressivamente diferenciados em termos de detalhes e especificidades durante o restante da aula, com a participação ativa dos alunos reunidos em pequenos grupos. A reconciliação integrativa é feita no início da aula seguinte, quando os resultados atingidos na aula anterior são comentados pelo professor e discutidos no grande grupo.

A respeito da teoria de Vygotsky (2001), levamos em consideração que o desenvolvimento cognitivo do ser humano não pode ser compreendido sem referência ao contexto social, sendo a interação social a componente principal para a transmissão dinâmica (de inter para intrapessoal) do conhecimento. Segundo Vygotsky (2001), a interação social que provoca a aprendizagem deve ocorrer dentro da zona de desenvolvimento proximal (ZDP), na qual se situam os problemas que o aprendiz não é capaz de resolver individualmente, mas é capaz de

\footnotetext{
${ }^{4}$ Esse método tem sido utilizado, ao longo do tempo, nas aulas teóricas ministradas pelo Prof. Dr. Marco Antonio Moreira, do Instituto de Física da Universidade Federal do Rio Grande do Sul. 
resolvê-los com orientação ou em colaboração com companheiros mais capazes (DRISCOLL, 1995 apud MOREIRA, 1999, p. 116).

A fim de promover uma interação social que propicie aprendizagem, após a exposição inicial, nas aulas que envolvem $\mathrm{AC}$ e $\mathrm{AE}$, os alunos recebem um guia impresso contendo questões dissertativas a serem respondidas em pequenos grupos. Nas demais aulas, após a exposição inicial do professor, os alunos resolvem, em pequenos grupos, problemas do livrotexto (HALLIDAY; RESNICK, 2003). Ao final de cada aula, os alunos são solicitados a entregar uma única solução por grupo das questões respondidas, para fins de avaliação formativa. Com a exigência de uma única solução por grupo, esperamos promover a negociação de significados entre os alunos. Para promover o engajamento cognitivo e a interatividade dos alunos, entre si e com os recursos instrucionais, concebemos os guias segundo um método que denominamos de PIE - Predizer, Interagir e Explicar - adaptado do método POE Predizer, Observar e Explicar - proposto por Tao e Gunstone (1999). No PIE, inicialmente, são apresentadas perguntas sobre a evolução de determinada situação física, e os alunos são convidados a predizer - antes de qualquer interação com o recurso computacional ou experimental - o que acontecerá. A seguir, os alunos devem interagir com a simulação computacional ou com o material experimental para gerarem resultados e, então, avaliarem o que efetivamente ocorre; e, finalmente, devem explicar as divergências e convergências de suas previsões em relação ao que foi observado.

Como marco teórico além das teorias de Ausubel (2003) e Vygotsky (2003), nos baseamos na visão epistemológica de Mario Bunge (1974). Para Bunge (1974), o único método eficaz para representar a realidade pelo pensamento é converter sistemas físicos em imagens conceituais e expandir em modelos teóricos progressivamente complexos e mais fiéis aos fatos. Por isso, ele defende que a busca pela conquista conceitual da realidade deve começar por idealizações, para, então, adicionar elementos imaginários (ou hipotéticos) com intenção realista, e, assim, constituir um objeto-modelo (modelo conceitual), que, inserido em uma teoria geral, pode gerar um sistema hipotético-dedutivo particular (modelo teórico/teoria específica). Os modelos conceituais têm a função de representar esquematicamente traços-chave de sistemas físicos, e os modelos teóricos de especificar o comportamento e/ou mecanismos internos de sistemas físicos particulares. Resultados empíricos, ao lado de hipóteses teóricas geradas a partir de modelos teóricos, proporcionam alguma evidência acerca dos contextos de validade dos modelos teóricos, isto é, o grau de precisão em que os traços-chave selecionados para construção do modelo conceitual são capazes de representar o sistema físico como um todo. Utilizamos essas ideias de Bunge (1974) para conceber atividades que propiciem a exploração dos contextos de validade dos modelos teóricos subjacentes às simulações computacionais. Por exemplo, em uma AC sobre associação de resistores em paralelo, inicialmente, os alunos devem predizer o comportamento das correntes elétricas It, I1, I2, ao se fechar a chave A-B no circuito mostrado na Figura 1, a. A seguir, os alunos devem interagir com a simulação para gerarem resultados que possibilitem perceber que I1 e I2 permanecem constantes ao se inserir ou retirar o terceiro resistor do circuito. $\mathrm{Na}$ sequência, os alunos devem montar um circuito elétrico real com duas lâmpadas associadas em paralelo e explicar por que, neste caso, ao se inserir uma terceira lâmpada em paralelo, a corrente elétrica em todas as lâmpadas é alterada (Figura 1, b). Para auxiliá-los a perceberem o que interfere nos resultados experimentais, fornecemos uma simulação (Figura 1, c) que propicia uma visualização geral de um circuito com fonte real. À 
medida que eles interagem com a simulação, devem perceber que, quando a fonte do circuito é real, ao se inserir outro resistor em paralelo, a diferença de potencial em cada resistor se altera. Essa alteração é maior, quanto maior a intensidade de corrente elétrica no circuito, pois maior é a queda de diferença de potencial devido à resistência interna da fonte. Finalmente, devem captar que se a resistência interna da fonte for muito menor que a resistência equivalente, a influência da resistência interna será mínima e o modelo computacional com uma fonte ideal poderá representar com maior grau de precisão o circuito real.

Em nossa proposta didática, sugerimos a integração entre AC e AE, desenvolvidas em dois momentos: em um primeiro, como preparação para a parte experimental, os alunos trabalham com computador; em um segundo momento, realizam um experimento real e exploram uma simulação sobre o experimento, para responderem questões conceituais presentes em guias impressos. Sempre que possível é desejável instigá-los para discriminarem sistemas reais e ideais. Isso não exclui a possibilidade que, em determinadas aulas, os alunos trabalhem somente com o computador ou somente com experimentos.

\section{Fundamentação metodológica da pesquisa}

Nesse estudo adotamos uma metodologia do tipo estudo de caso (YIN, 2005). Segundo Yin (2005), um estudo de caso é uma investigação empírica que: i) investiga um fenômeno contemporâneo dentro do seu contexto de vida real; ii) mostra-se adequada quando as questões de pesquisa são do tipo "como?" e "por quê?”; iii) pode se beneficiar do desenvolvimento prévio de proposições norteadoras; iv) enfrenta uma situação tecnicamente única em que haverá muito mais variáveis de interesse do que pontos de dados, e v) se baseia em várias fontes de evidências (por exemplo: entrevistas e observações direta e participante).

Figura 1. (a) Diagrama de um circuito elétrico simples com resistores associados em paralelo. (b) Circuito elétrico real com lâmpadas associadas em paralelo. No multiteste, é medida a diferença de potencial em cada lâmpada. Na foto da esquerda, com duas lâmpadas conectadas, a diferença de potencial no multiteste é igual a 8,84V e, na da direita, com três lâmpadas, é igual a 7,97V. (c) Janela Animação 1 de uma simulação computacional sobre um circuito com fonte real

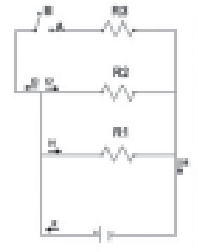

(a)

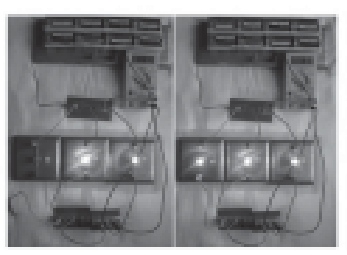

(b)

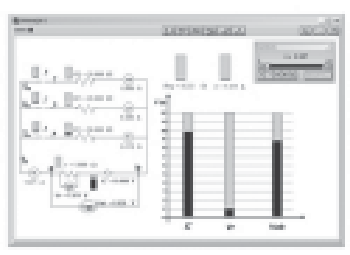

(c)

Fonte: Dorneles (2010). 
Para Yin (2005), os principais componentes de um projeto de estudo de caso são: as questões de pesquisa, as proposições norteadoras, se houver, a(s) unidade(s) de análise, a lógica que une os dados às proposições, e os critérios para se interpretarem as constatações. Em relação às proposições, Yin (2005) argumenta que elas, além de refletirem questões teóricas importantes, direcionam a atenção do investigador ao que deve ser investigado dentro do propósito do estudo.

Um estudo de caso pode envolver um único indivíduo ou uma única instituição (caso único), mas também pode envolver um grupo de indivíduos ou várias instituições (casos múltiplos). Por exemplo: pacientes clínicos, alunos de uma turma, escolas, empresas etc. Em ambos os casos, cada indivíduo ou instituição será a unidade primária de análise. No método de estudo de casos múltiplos, para cada caso, o relatório individual deve indicar como e por que se demonstrou (ou não) uma proposição. Os casos devem seguir a lógica da replicação prever resultados semelhantes ou produzir resultados contrastantes apenas por razões previsíveis. Quando ocorrer uma situação em que houve um achado ou constatação durante a realização de um estudo de caso individual, é necessário reformular a teoria inicial antes de se continuar avançando. Se o achado for ignorado ou distorcido para acomodar o projeto original, corre-se o risco de o estudo receber a crítica de que os dados foram adaptados às ideias preconcebidas (YIN, 2005).

Segundo Yin (2005), estudos de casos podem apresentar propósitos diferentes, sendo os principais: descritivo, exploratório e explanatório. Um estudo descritivo tem o objetivo de descrever uma intervenção dentro do contexto em que ela ocorreu. O exploratório busca um levantamento de hipóteses ou proposições norteadoras para embasarem pesquisas futuras.

Nesses estudos, geralmente, a intervenção que está sendo investigada não apresenta um conjunto simples e claro de resultados. Já o explanatório tem o objetivo de explicar relações de causa e efeito a partir de proposições norteadoras. Classificamos o presente estudo do tipo explanatório de casos múltiplos (cada aluno constitui um caso).

\section{Esquema de avaliação}

No Quadro 1, vinculamos as proposições norteadoras com as variáveis a serem medidas ao longo do estudo e os instrumentos de medidas utilizados para medir tais variáveis.

Quadro 1. Relação entre proposições norteadoras, variáveis medidas e instrumentos de medidas

\begin{tabular}{|c|l|l|}
\hline Proposições norteadoras & \multicolumn{1}{|c|}{ Variáveis medidas } & \multicolumn{1}{|c|}{ Instrumentos de medida } \\
\hline 1 & $\begin{array}{l}\text { Visão do papel de modelos teóricos } \\
\text { Visão do papel do laboratório } \\
\text { Visão do papel do computador }\end{array}$ & $\begin{array}{l}\text { Entrevista semiestruturada } \\
\text { Questões dissertativas } \\
\text { Notas de campo } \\
\text { Guias preenchidos } \\
\text { Teste sobre a natureza da Ciência }\end{array}$ \\
\hline \multirow{2}{*}{2} & Motivação & $\begin{array}{l}\text { Guias preenchidos } \\
\text { Entrevista semiestruturada }\end{array}$ \\
\hline & Significância do material & $\begin{array}{l}\text { Questões de prova } \\
\text { Guias preenchidos }\end{array}$ \\
\hline
\end{tabular}

Fonte: Dorneles (2010). 
A Figura 2 ilustra o esquema de avaliação empregado. Para analisar a aprendizagem significativa, por parte dos alunos, do conteúdo de eletromagnetismo em nível de física geral, realizamos medidas sobre a aprendizagem conceitual, a motivação e a significância, para cada aluno, do material instrucional proposto. Essas variáveis foram adotadas porque, para Ausubel (2003), há duas condições para ocorrência da aprendizagem significativa, quais sejam, é necessário que: i) o aluno manifeste disposição para relacionar o novo material, potencialmente significativo, de forma substantiva e não arbitrária, à sua estrutura cognitiva; ii) o material seja potencialmente significativo, isto é, tenha estruturação lógica que possibilite que um indivíduo interessado, que possua em sua estrutura cognitiva subsunçores adequados, aprenda as novas informações nele contidas. Para que o material seja efetivamente significativo para um indivíduo em particular, duas condições devem ser satisfeitas: o material deve ter estruturação lógica adequada e o indivíduo possuir os subsunçores apropriados em sua estrutura cognitiva.

Figura 2. Esquema de avaliação de nossa proposta didática (DORNELES, 2010).

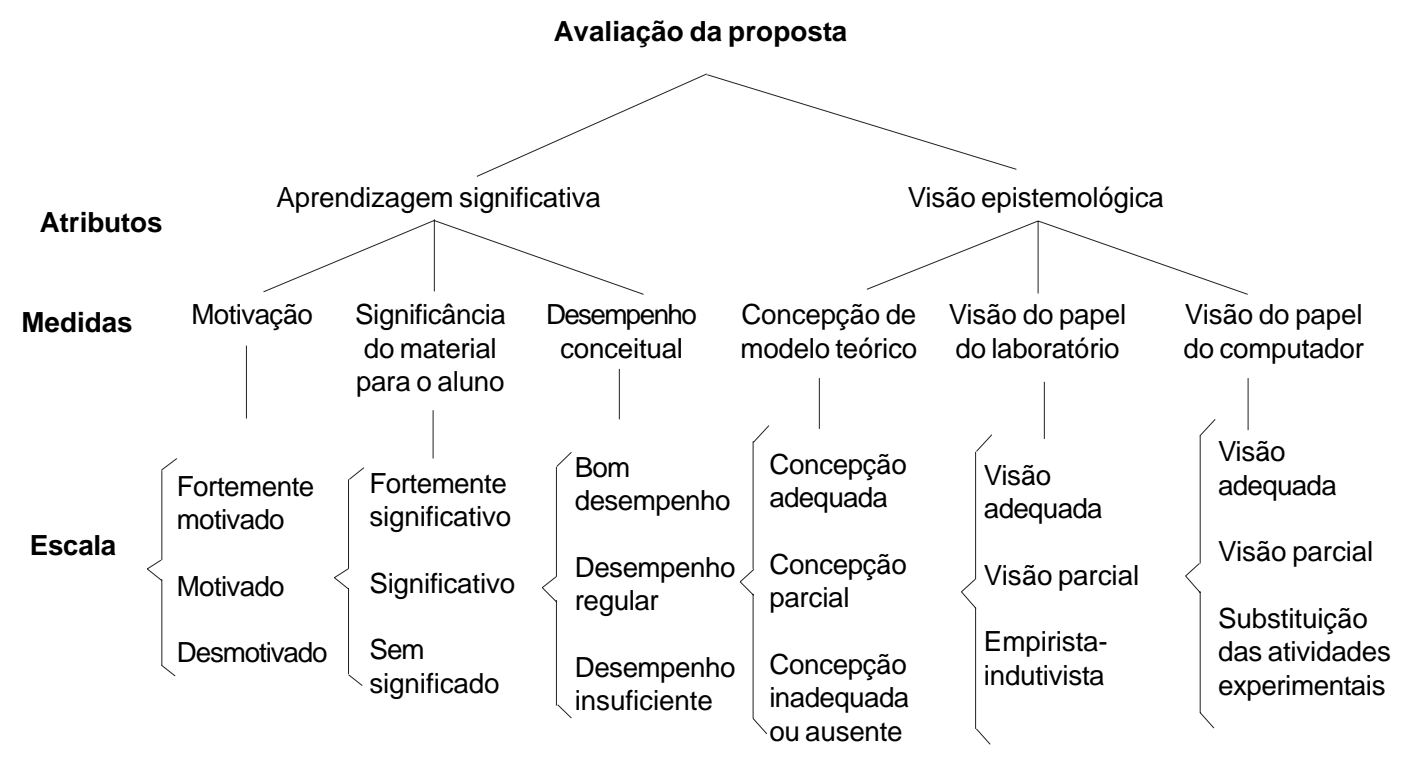

Consideramos que nosso material possui estrutura lógica, pois foi validado por dois especialistas no assunto (professores das aulas teóricas e experimentais, segundo e terceiro autor do presente trabalho, respectivamente). Em relação aos alunos possuírem conhecimento prévio em sua estrutura cognitiva, para acompanharem as explicações e os raciocínios propostos no material, buscamos indicadores sobre o desempenho dos alunos nas tarefas e opiniões sobre o material. 
Integração entre atividades computacionais ...

Em relação ao desenvolvimento de uma concepção adequada sobre Ciência, buscamos medir a compreensão dos alunos a respeito dos modelos teóricos empregados e do papel do laboratório e do uso do computador em Física. Nossa expectativa era a de que ao se concluir o procedimento didático os alunos percebessem os modelos teóricos como construtos físicos que são desenvolvidos com o objetivo de representarem parcialmente sistemas reais. Deveriam, ainda, perceber que: i) os referentes diretos dos modelos teóricos são sistemas ideais, e não sistemas reais; ii) que hipóteses teóricas são corroboradas com dados experimentais somente se os parâmetros considerados desprezíveis nos modelos teóricos não influenciarem significativamente as medidas experimentais; iii) que, nesse caso, o modelo teórico é capaz de representar, com certo grau de precisão, o comportamento de grandezas físicas presentes no sistema real, e, iv) caso contrário, faz-se necessário incluir outros efeitos para aperfeiçoar o modelo ou construir outro completamente diferente. Para isso, não planejamos introduzir, em sala de aula, conceitos básicos da epistemologia de Bunge (1974), como são os conceitos de objeto-concreto, de objeto-modelo (modelo conceitual), de modelo teórico (teoria específica), mas, simplesmente, levar em conta tais conceitos na readaptação das atividades propostas nos estudos anteriores, para que as atividades integradas promovessem a reflexão dos alunos sobre as idealizações e o domínio de validade dos modelos teóricos.

Em relação ao papel do laboratório, desejávamos que os alunos percebessem a prática experimental como um recurso capaz de: i) intensificar a aprendizagem de conceitos científicos; ii) propiciar a exploração do contexto de validade de modelos teóricos; iii) proporcionar a integração entre teoria e realidade; iv) estimular a geração e teste de hipóteses; enfim, adquirissem "uma visão de que a ciência contemporânea não é apenas experimentação e sim teoria mais experiência, executada e interpretada à luz de teorias" (BUNGE, 1974, p. 10). Em outras palavras, que modelos teóricos versam sobre sistemas físicos que geram previsões teóricas, confrontadas com evidências encontradas a partir de dados experimentais obtidos e interpretados à luz de teorias instrumentais já consolidadas. Sobre o papel do computador, esperamos que os alunos o considerassem como um recurso instrumental capaz de: intensificar a aprendizagem de conceitos científicos; propiciar uma visualização mais geral e imediata de sistemas idealizados, comparada com representações estáticas; tornar mais dinâmica a comparação entre sistemas ideais e reais; facilitar o entendimento sobre modelos teóricos, e estimular a geração e teste de hipóteses.

\section{Apresentação e discussão dos resultados}

Para avaliar a visão epistemológica dos alunos, na primeira aula foi aplicado um teste sobre a natureza da Ciência ${ }^{5}$, com dez questões de múltipla escolha e duas dissertativas, constantes no Apêndice A. Ao final da disciplina, as questões de múltipla escolha e as dissertativas (Apêndice B) foram reaplicadas como pós-teste, sendo que uma das questões dissertativas foi alterada devido a problemas de adequação. $O$ teste foi validado com uma população de 67

${ }^{5}$ Disponível em: <http://www.if.ufrgs.br/cref/ntef/circuitos/teste_ciencia.pdf>. Acesso em: 16 jan. 2012. 
alunos do curso de Física, resultando em um coeficiente alfa de Cronbach de 0,72. Cada item do teste contém uma afirmativa coerente ou incoerente com uma visão contemporânea de ciências. Às afirmativas coerentes (2, 5, 6, 9 e 10), atribuímos a pontuação 5, 4, 3, 2, e 1 às alternativas concordo fortemente (CF), concordo (C), indeciso (I), discordo (D) e discordo fortemente (DF), respectivamente. As demais afirmativas $(1,3,4,7,8)$ foram pontuadas de modo inverso, ou seja, 1, 2, 3, 4 e 5. Salientamos que aplicamos esse teste com o objetivo de ter uma visão inicial sobre as concepções dos alunos e para triangular com nossas inferências oriundas dos dados qualitativos, não para fazer qualquer inferência estatística. A evolução dos alunos do pré para o pós-teste pode ser visualizada na Figura 3.

Figura 3. Resultados do pré e pós-teste mostrando a evolução dos escores (a) totais dos seis alunos em cada afirmativa (escore máximo $=30$ ) e $(b)$ de cada aluno nos dez itens do teste - escore máximo = 50 .

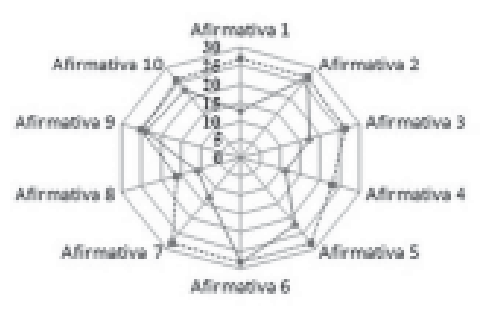

(a)

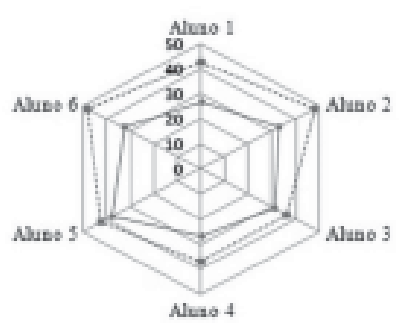

(b)

Fonte: Dorneles (2010).

Observam-se, no gráfico da Figura 3 (a), escores baixos no pré-teste na afirmativa 1, que está relacionada ao contexto de validade das teorias científicas, e nas afirmativas 4 e 8 , relacionadas à visão empirista-indutivista da Ciência. No pós-teste, apenas a afirmativa 8 permaneceu com escore baixo, passando de 11 para 16 pontos. Observa-se, na Figura 3 (b), que dos alunos que obtiveram um escore baixo no pré-teste, apenas os alunos 3 e 4 não atingiram um escore próximo do máximo no pós-teste. Para triangular com esses dados, levamos em conta as diversas fontes de dados qualitativos (Quadro 1), e, como ilustração, apresentamos os quadros 2 a 7, com resultados para cada um dos alunos sobre os atributos visão epistemológica e aprendizagem significativa. Conforme a Figura 2, para se avaliar a visão epistemológica, foram feitas medidas sobre: concepção de modelos teóricos, visão do papel do laboratório didático e do computador. Para isso, utilizamos dados das entrevistas semiestruturadas (Apêndice C), realizadas na aula 16 (quando já tínhamos $60 \%$ do estudo concluído), e de questões dissertativas respondidas ao final da disciplina (Apêndice B). Em relação à aprendizagem 
significativa, realizamos medidas da motivação, significância do material para o aluno e desempenho conceitual. Nessa avaliação, consideramos que o material é composto pelos modelos computacionais, pelos experimentos montados, pelos guias de atividades e trechos do livro-texto (HALLIDAY; RESNICK; WALKER, 2003). Para as medidas de motivação e significância do material, transcrevemos, na quarta coluna dos quadros 2-7, trechos da entrevista semiestruturada e das gravações realizadas enquanto os alunos desenvolviam as atividades. Em relação ao desempenho conceitual, nos restringimos aos conceitos de: força eletromotriz (fem) induzida, resistência elétrica em circuitos simples, potência de saída de uma fonte e frequência de ressonância em circuitos $\mathrm{CA}^{6}$. Como ilustração do desempenho conceitual, apresentamos somente alguns dados coletados referentes ao conceito de resistência elétrica em circuitos simples, extraídos de uma questão da segunda avaliação da disciplina ${ }^{7}$. A última coluna dos quadros 2 a 7 contém um comentário interpretativo a respeito do aluno ao qual o quadro se refere em relação à medida considerada, ancorado em todos os dados coletados ao longo do estudo, não somente nos dados apresentados na própria tabela. Também o nível em que classificamos o aluno na escala considerada para cada medida (terceira coluna) leva em conta todos os dados coletados. Construímos os quadros 2-7 com o objetivo de mostrar alguns dos elementos e regularidades que consideramos na análise da corroboração ou não das proposições norteadoras que embasaram o desenvolvimento e a coleta de dados. A título de esclarecimento, salientamos que a análise que segue está ancorada em todos os dados que coletamos ao longo do estudo, e não apenas nos fragmentos utilizados para ilustrar a argumentação/opinião dos alunos em cada tópico apresentado nos quadros.

Em relação à proposição 1 , que diz respeito à concepção de modelos teóricos e aos papéis do laboratório e do computador, a análise dos dados coletados, sintetizada nos quadros 2 a 7 , nos leva a dizer que:

. em relação à concepção de modelos teóricos, constatamos que todos os alunos, em algumas circunstâncias, refletiram sobre os contextos de validade dos modelos teóricos envolvidos nas atividades propostas ao longo do semestre. Consideramos que os alunos 1, $3 \mathrm{e}$ 4 apresentaram uma concepção adequada, pois explicitaram e deram exemplos, na entrevista, de que modelos teóricos possuem idealizações e buscam representar sistemas reais. Parecenos que os alunos 2 e 6 perceberam as diferenças entre os sistemas ideais e reais, mas não explicitaram mais elementos. Então, supomos que eles atingiram uma concepção parcial acerca de modelos teóricos, enquanto o Aluno 5 apresentou uma concepção inadequada. Para ele: "modelos teóricos são o produto acabado da elaboração intelectiva que consiste em observação, hipótese, experimento e teoria". Visão inadequada que explicita uma concepção impregnada de ideias de um método científico que possui uma sequência regida de procedimentos, possivelmente relacionada ao conhecimento científico do curso que ele fazia paralelamente (Medicina);

- no que diz respeito ao papel do laboratório didático de Física, todos os alunos, ao final do semestre, se mostraram insatisfeitos com atividades fortemente dirigidas e que te-

\footnotetext{
${ }^{6}$ Não avaliamos outros conceitos relevantes, como os conceitos de campo elétrico e magnético, força elétrica e magnética e energia eletromagnética, porque esses foram trabalhados com mais ênfase nas aulas teóricas, que não fizeram parte de nosso procedimento didático.

${ }^{7}$ Disponível em: <http://www.if.ufrgs.br/cref/ntef/circuitos/questao_prova.pdf>. Acesso em: 16 jan. 2012.
} 
Dorneles, P. F. T.; Araujo, I. S.; Veit, E. A.

nham como principal objetivo o de "determinar a lei" física subjacente aos fenômenos investigados. Conforme relatamos nas análises individuais, apenas o Aluno 4 não atingiu uma visão adequada ou parcial acerca do papel do laboratório; os demais alunos apresentaram argumentos que mostram que perceberam as atividades experimentais, propostas nesse estudo, como um recurso capaz de propiciar a exploração do contexto de validade de modelos teóricos; proporcionar um vínculo entre teoria e realidade, e estimular a geração e teste de hipóteses;

- quanto ao papel do computador todos os alunos destacaram que a visualização é a principal característica positiva, e deram indícios de que as atividades computacionais auxiliaram: i) a terem uma visão geral do experimento, ii) a analisarem o domínio de validade dos modelos teóricos, iii) no entendimento fenomenológico das equações de Maxwell, e iv) na reificação de conceitos abstratos. Com isso, entendemos que todos tenham atingido uma visão adequada. Cabe salientar que nenhum aluno explicitou espontaneamente que prefere a substituição das atividades de laboratório pelas computacionais.

Quadro 2. Resultados e classificação do Aluno 1

\begin{tabular}{|c|c|c|c|c|}
\hline \multicolumn{2}{|c|}{ Aluno 1} & \multirow[b]{2}{*}{ 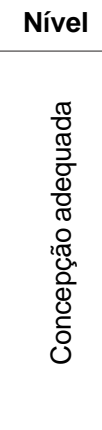 } & \multirow[b]{2}{*}{\begin{tabular}{|l}
\multicolumn{1}{|c}{ Depoimento } \\
Eu acho que é ótimo essa diferenciação \\
entre um sistema real e um sistema ideal, \\
porque estamos acostumados com uma \\
situação ideal [...] Pensei assim já várias \\
vezes até que ponto a gente pode dizer \\
que a situação é ideal, não só nos \\
circuitos. No laboratório a gente faz \\
limpeza dos substratos, mas logo depois \\
da limpeza ele já está exposto, aí já tem a \\
contaminação e tal. Até que ponto esse \\
erro não interfere?
\end{tabular}} & \multirow{2}{*}{\begin{tabular}{l}
\multicolumn{1}{c}{ Comentário interpretativo } \\
Ao fazer a discriminação entre sistemas \\
reais e ideais, esse aluno, além de se \\
mostrar motivado, foi capaz de estabelecer \\
um vínculo entre os modelos teóricos e os \\
sistemas reais.
\end{tabular}} \\
\hline & 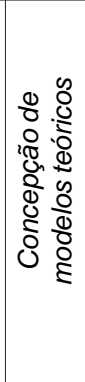 & & & \\
\hline & $\begin{array}{l}: 0 \\
\frac{0}{0} \\
\frac{0}{0} \\
\frac{\pi}{\pi} \\
\frac{0}{0} \\
\frac{0}{d} \\
\frac{2}{\sigma}\end{array}$ & 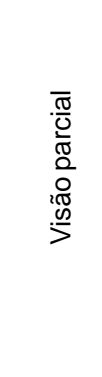 & $\begin{array}{l}\text { Fazer e visualizar experimentalmente o } \\
\text { que é visto na teoria. Mostrar } \\
\text { principalmente o que é real e o que é o } \\
\text { ideal na hora da experimentação. Eu acho } \\
\text { ótimo isso. Na Física 1, } 2 \text { e no laboratório } \\
\text { o professor dava a "receitinha"[...], estava } \\
\text { tudo explicado. Era só fazer aquilo lá, não } \\
\text { tinha muita ideia física. Era muita conta, } \\
\text { mas não era muita interpretação que nem } \\
\text { agora. Não tinha tanta interpretação física } \\
\text { como agora. }\end{array}$ & $\begin{array}{l}\text { Apesar de ele ter praticamente restringido o } \\
\text { laboratório em um recurso instrucional que } \\
\text { serve para ilustrar as teorias apresentadas } \\
\text { nas aulas expositivas, em outros momentos } \\
\text { apresentou indícios que superam essa } \\
\text { concepção. Por exemplo, destacou, de } \\
\text { forma positiva, que, nas aulas } \\
\text { experimentais, teve muita interpretação } \\
\text { física, diferentemente dos laboratórios } \\
\text { anteriores onde se priorizavam } \\
\text { procedimentos fortemente dirigidos. }\end{array}$ \\
\hline & 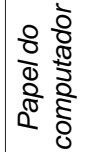 & 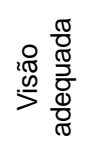 & $\begin{array}{l}\text { Ajudar na visualização de experimentos, } \\
\text { dando muitas vezes ideias de como se dá } \\
\text { alguns funcionamentos físicos que na } \\
\text { verdade não são vistos, são abstratos. }\end{array}$ & $\begin{array}{l}\text { Ele destacou a reificação de conceitos } \\
\text { abstratos e a diferenciação entre sistemas } \\
\text { ideais e reais como os principais pontos } \\
\text { positivos das AC. }\end{array}$ \\
\hline
\end{tabular}


Integração entre atividades computacionais ...

Quadro 2. continuação

\begin{tabular}{|c|c|c|c|c|}
\hline \multicolumn{2}{|c|}{ Aluno 1} & \multirow[b]{2}{*}{ 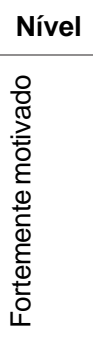 } & \multirow{2}{*}{\begin{tabular}{l}
\multicolumn{1}{c}{ Depoimento } \\
Eu acho ótimo isso. Na Física 2 e Física 1 \\
no laboratório o professor dava a \\
"receitinha" ali e tal, estava tudo explicado. \\
Era só fazer aquilo lá, não tinha muita \\
idéia física. Era muita conta, mas não era \\
muita interpretação que nem agora. Não \\
tinha tanta interpretação física como \\
agora.
\end{tabular}} & \multirow{2}{*}{\begin{tabular}{l}
\multicolumn{1}{c}{ Comentário interpretativo } \\
Ao longo do semestre, observamos seu \\
entusiasmo nas discussões com seu \\
colega de grupo, sempre interagindo de \\
forma consciente e motivado pelo \\
aprendizado dos conceitos físicos.
\end{tabular}} \\
\hline \multirow{3}{*}{ 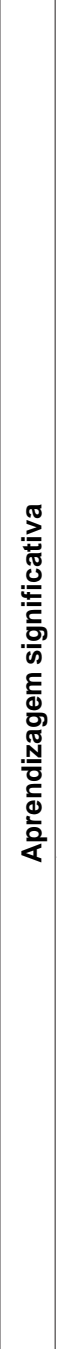 } & 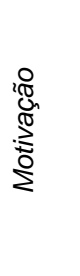 & & & \\
\hline & 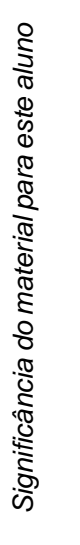 & 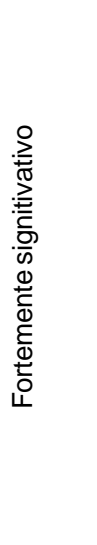 & $\begin{array}{l}\text { A gente fez no computador, claro que } \\
\text { ajudou com certeza. É que primeiro era } \\
\text { para dar ideias se a gente achava que } \\
\text { dava e depois a gente ia para a simulação } \\
\text { para ver se era isso mesmo. E depois } \\
\text { para o experimento. Até nesse sentido o } \\
\text { computador, nessa aula, ajudou muito } \\
\text { mais que o experimento, eu acho. }\end{array}$ & $\begin{array}{l}\text { Nesse trecho, o aluno se refere à aula em } \\
\text { que trabalhou com circuito integrador e } \\
\text { diferenciador. Ele e seu colega de grupo } \\
\text { (Aluno2) não foram capazes de perceber o } \\
\text { significado físico das curvas mostradas no } \\
\text { osciloscópio. Essa era a segunda vez que } \\
\text { utilizavam o osciloscópio e observamos que } \\
\text { estavam inibidos e inseguros com seu } \\
\text { manuseio. Mas isso não passou de uma } \\
\text { dificuldade inicial. Por exemplo, na última } \\
\text { aula sobre corrente alternada, esse aluno } \\
\text { foi capaz de acompanhar os procedimentos } \\
\text { e raciocínios presentes no guia, para } \\
\text { encontrar, com o uso do osciloscópio, a } \\
\text { frequência de ressonância de um circuito } \\
\text { RLC em série. }\end{array}$ \\
\hline & 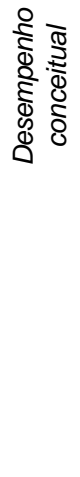 & 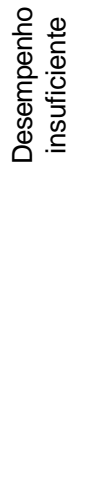 & $\begin{array}{l}\text { Quando fechamos a chave A-B, temos } \\
\text { duas lâmpadas em paralelo. A resistência } \\
\text { equivalente vale a metade da inicial. Logo, } \\
\text { a corrente dobra de valor. Como a } \\
\text { corrente se divide, cada lâmpada recebe } \\
\text { a mesma quantidade de corrente, como } \\
\text { no caso da chave } A-B \text { aberta, a potência, } \\
\text { ou seja, o brilho da lâmpada } L 1 \text { não muda } \\
(P=i 2 R) .{ }^{*} \\
\text { "Resposta à questão de prova. Disponível } \\
\text { em: <http://www.if.ufrgs.br/cref/ntef/ } \\
\text { circuitos/questao_prova.pdf }>\text {. Acesso em: } \\
16 \text { jan. } 2012 \text {. }\end{array}$ & $\begin{array}{l}\text { Ao longo do semestre, seu grupo } \\
\text { preencheu completamente o guia proposto, } \\
\text { apresentando respostas com } \\
\text { argumentação física consistente, que nos } \\
\text { levam a supor que ele percebeu o } \\
\text { significado dos conceitos físicos em } \\
\text { discussão. Apesar de não ter levado em } \\
\text { consideração a resistência interna da fonte, } \\
\text { foi capaz de relacionar, de forma adequada, } \\
\text { os conceitos de corrente elétrica e } \\
\text { resistência equivalente para uma } \\
\text { associação de resistores em paralelo, } \\
\text { conforme trecho transcrito ao lado. }\end{array}$ \\
\hline
\end{tabular}

Fonte: Dorneles (2010). 
Dorneles, P. F. T.; Araujo, I. S.; Veit, E. A.

Quadro 3. Resultados e classificação do Aluno 2

\begin{tabular}{|c|c|c|c|c|}
\hline \multicolumn{2}{|c|}{ Aluno 2} & \multirow{2}{*}{ 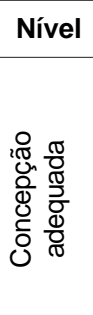 } & \multirow{2}{*}{\begin{tabular}{l}
\multicolumn{1}{c}{ Depoimento } \\
Elucidar o comportamento de sistemas \\
idealizados. \\
Eu gostei bastante porque tu pega um \\
sistema idealizado no computador ali tudo \\
dá certo daí depois tu bota uma prática ali e \\
vê se acontece aquilo mesmo se é válido \\
aquilo ali.
\end{tabular}} & \multirow{2}{*}{\begin{tabular}{l}
\multicolumn{1}{c}{ Comentário interpretativo } \\
Ele demonstrou ter refletido sobre os \\
contextos de validade dos modelos teóricos \\
envolvidos nas atividades propostas ao \\
longo do semestre, mas não explicitou e \\
nem deu exemplos durante a entrevista.
\end{tabular}} \\
\hline \multirow{3}{*}{ 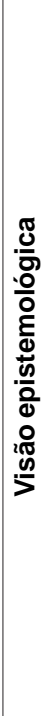 } & $\begin{array}{ll} & n \\
0 & 0 \\
0 & 0 \\
2 & 0 \\
0 & 0 \\
0 & 0 \\
0 & 0 \\
0 & 0 \\
0 & 0 \\
0 & 0 \\
0 & \varepsilon\end{array}$ & & & \\
\hline & 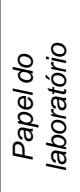 & 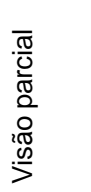 & $\begin{array}{l}\text { A teoria que tu vê no livro é baseada em } \\
\text { idealizações tu vai para o laboratório e } \\
\text { começa a fazer os experimentos, coletar } \\
\text { dados, e percebe o que está fechando com } \\
\text { aquela fórmula com aquela teoria e tal. }\end{array}$ & $\begin{array}{l}\text { Apresentou indícios de que o ensino de } \\
\text { laboratório não é só experimentação, e sim } \\
\text { teoria mais experiência. Também destacou } \\
\text { que as AE devem privilegiar a reflexão e a } \\
\text { criatividade. }\end{array}$ \\
\hline & 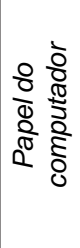 & & $\begin{array}{l}\text { O computador dá uma base para } \\
\text { compreender o que está acontecendo na } \\
\text { parte real do experimento. Tu vê no } \\
\text { computador. Aí vai olhar no livro por que } \\
\text { está acontecendo assim? Aí já se tem } \\
\text { uma base sobre o que está acontecendo } \\
\text { para montar na prática o experimento. }\end{array}$ & $\begin{array}{l}\text { Destacou que o computador pode propiciar } \\
\text { uma visão mais geral dos sistemas físicos } \\
\text { e pode constituir uma preparação para o } \\
\text { desenvolvimento de AE. }\end{array}$ \\
\hline \multirow{3}{*}{ 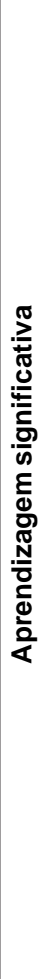 } & 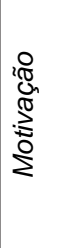 & 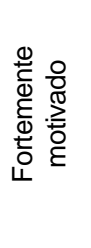 & $\begin{array}{l}\text { Eu não cheguei a terminar as aulas de } \\
\text { laboratório no semestre passado, mas } \\
\text { esse laboratório eu achei bem mais } \\
\text { interessante. A interação com o grupo } \\
\text { também foi bem mais interessante. O } \\
\text { computador ali também. }\end{array}$ & $\begin{array}{l}\text { Essa manifestação tanto pode ser devida a } \\
\text { uma efetiva evolução de nossa proposta } \\
\text { didática do estudo anterior para o presente, } \\
\text { quanto devida ao fato de que, da primeira } \\
\text { vez, participando de uma única aula, não } \\
\text { lhe foi suficiente para captar o espírito da } \\
\text { proposta. }\end{array}$ \\
\hline & 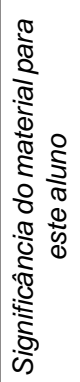 & 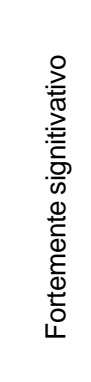 & $\begin{array}{l}\text { Ah, eu acho importante cara, eu acho que } \\
\text { algumas idealizações que tem nos } \\
\text { problemas, ali pelo computador tu pode } \\
\text { ver bem direitinho tu não precisa fazer um } \\
\text { experimento todo montar um experimento } \\
\text { todo para resolver um problema ou para } \\
\text { ter uma opinião sobre um problema... Eu } \\
\text { gostei bastante, esse último laboratório eu } \\
\text { gostei mais por que não tinha tantos } \\
\text { dados, era um negócio mais intuitivo } \\
\text { chegava rápido ao objetivo do laboratório. }\end{array}$ & $\begin{array}{l}\text { Sua característica marcante foi a atitude de } \\
\text { buscar entender os procedimentos } \\
\text { necessários para preencher os guias. Sua } \\
\text { opinião sobre as AC e AE evidenciam que } \\
\text { ele foi capaz de perceber os objetivos das } \\
\text { atividades propostas, o que propiciou uma } \\
\text { forte interação com os recursos } \\
\text { instrucionais e a apresentação de } \\
\text { respostas nos guias com justificativas } \\
\text { físicas, em praticamente todas as aulas. }\end{array}$ \\
\hline & 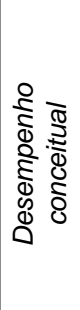 & 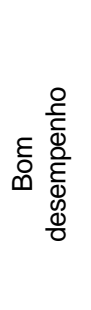 & $\begin{array}{l}L_{1} \text { continua com mesmo brilho ao fechar a } \\
\text { chave } A-B, \text { pois neste caso a diferença de } \\
\text { potencial é constante, o circuito está em } \\
\text { paralelo }\left(P=V^{2} / R\right) \text {. Assim o brilho se } \\
\text { mantém constante, mas se } R_{L} \text { fosse da } \\
\text { mesma ordem de grandeza de r uma boa } \\
\text { parte da potência fornecida pela fonte } \\
\text { seria dissipada em r diminuindo o brilho da } \\
\text { lâmpada. }\end{array}$ & $\begin{array}{l}\text { Esse aluno, de forma semelhante ao Aluno } \\
1, \text { seu parceiro de dupla, apresentou, ao } \\
\text { longo do semestre, vários indícios de ter } \\
\text { atingido uma aprendizagem significativa. O } \\
\text { trecho transcrito ao lado é um exemplo de } \\
\text { que ele foi capaz de relacionar } \\
\text { significativamente o comportamento das } \\
\text { grandezas físicas presentes em circuitos } \\
\text { simples. }\end{array}$ \\
\hline
\end{tabular}

Fonte: Dorneles (2010). 
Integração entre atividades computacionais ...

Quadro 4. Resultados e classificação do Aluno 3

\begin{tabular}{|c|c|c|c|c|}
\hline \multicolumn{2}{|c|}{ Aluno 3} & \multirow{2}{*}{ 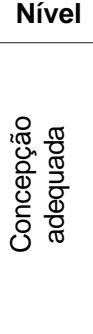 } & \multirow{2}{*}{\begin{tabular}{l}
\multicolumn{1}{c}{ Depoimento } \\
Serve como base para inícios de \\
experiências para saber como vai iniciar a \\
prática. Mas muitas vezes a teoria é bem \\
diferente da prática, pois na teoria existe \\
muitas vezes uma aproximação para que \\
os valores fiquem "elegantes". O modelo \\
teórico despreza alguns dados.
\end{tabular}} & \multirow[b]{2}{*}{$\begin{array}{l}\text { Comentário interpretativo } \\
\text { Esse aluno, também, apresentou argumentos } \\
\text { que sugerem que ele percebeu que os } \\
\text { modelos teóricos possuem idealizações e, } \\
\text { assim, um contexto de validade. Nas } \\
\text { questões dissertativas ele respondeu que o } \\
\text { progresso do conhecimento científico se dá } \\
\text { através de estudos teóricos e práticos, } \\
\text { hipóteses e modelos. }\end{array}$} \\
\hline 兽 & 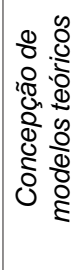 & & & \\
\hline & 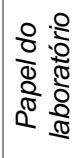 & 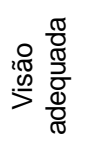 & $\begin{array}{l}\text { Poder comparar os resultados teóricos } \\
\text { com os práticos. Muitas vezes para se } \\
\text { chegar numa teoria e em outros casos } \\
\text { para verificar a teoria. }\end{array}$ & $\begin{array}{l}\text { Destacou as potencialidades do laboratório } \\
\text { em estabelecer um vínculo entre teoria e } \\
\text { realidade e de propiciar a exploração do } \\
\text { contexto de validade de modelos teóricos. }\end{array}$ \\
\hline$>$ & 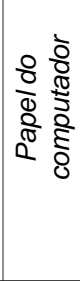 & & $\begin{array}{l}\text { Dava para você visualizar bem ali no } \\
\text { computador, você variava o que tinha que } \\
\text { variar e percebia o que acontecia. }\end{array}$ & $\begin{array}{l}\text { Em relação ao computador, ele considerou } \\
\text { que é uma ferramenta que auxilia na } \\
\text { visualização. No entanto, também destacou } \\
\text { que, em algumas atividades, o computador } \\
\text { foi desnecessário. Segundo ele, nas aulas } \\
\text { sobre circuitos } \mathrm{RL} \text { o uso do osciloscópio foi } \\
\text { suficiente para atingir os objetivos das } \\
\text { experiências. }\end{array}$ \\
\hline \multirow{3}{*}{ 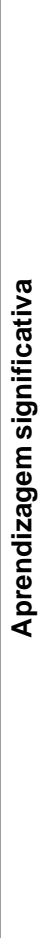 } & 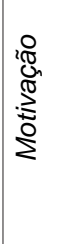 & 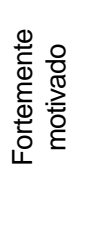 & $\begin{array}{l}\text { O laboratório talvez até desmotive } \\
\text { algumas pessoas porque às vezes vamos } \\
\text { para o laboratório sem conhecer o } \\
\text { assunto, então a experiência fica um } \\
\text { negócio mecanizado, sem entender o que } \\
\text { está acontecendo, preocupado só em } \\
\text { coletar dados para fazer o relatório. }\end{array}$ & $\begin{array}{l}\text { Na entrevista, ele destacou o vínculo entre } \\
\text { teoria e experimento como um elemento que } \\
\text { o motivou para o desenvolvimento das } \\
\text { atividades práticas. }\end{array}$ \\
\hline & 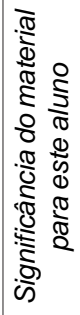 & 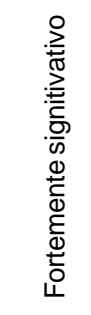 & $\begin{array}{l}\text { No princípio eu estava anotando o ângulo } \\
\text { porque cada vez que eu variava a } \\
\text { corrente o ângulo variava. Eu não sabia a } \\
\text { relação até o momento, depois que você } \\
\text { falou sobre as duas componentes aí é que } \\
\text { eu me liguei no significado do ângulo. }\end{array}$ & $\begin{array}{l}\text { Em quase todas as aulas, esse aluno } \\
\text { demonstrou ter interagido de maneira } \\
\text { significativa com os recursos instrucionais. } \\
\text { No entanto, em algumas aulas, mesmo já } \\
\text { tendo visto a parte teórica, ele começou a } \\
\text { interagir com os experimentos } \\
\text { mecanicamente, sem, inicialmente, refletir } \\
\text { sobre os procedimentos e pressupostos } \\
\text { teóricos envolvidos nas atividades. }\end{array}$ \\
\hline & 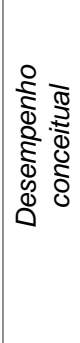 & 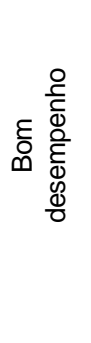 & $\begin{array}{l}\text { Se considerarmos } R_{L}>>r \text {, haverá uma } \\
\text { pequena variação no brilho da } L_{1} \\
\text { (diminuindo sua intensidade) ao fechar a } \\
\text { chave } A-B \text {. A potência aumenta } \\
\text { proporcionalmente com } R \text { até quando } R=r \text {, } \\
\text { assim a potência é máxima neste caso. A } \\
\text { potência dissipada em } R \text { e a dissipada na } \\
\text { fonte são iguais. Desconsidera a potência } \\
\text { dissipada na fonte quando } r<<R \text {. (Dado } \\
\text { complementar extraído dos guias) }\end{array}$ & $\begin{array}{l}\text { Esse aluno apresentou, na prova, uma } \\
\text { resposta correta, mas sem justificativa } \\
\text { convincente. Por isso, inserimos mais um } \\
\text { dado extraído do guia sobre uma simulação } \\
\text { de um circuito simples com uma fonte real, } \\
\text { em que ele demonstrou ter entendido } \\
\text { qualitativamente a influência da resistência } \\
\text { interna no circuito. Ao longo do semestre ele } \\
\text { apresentou diversos indícios de ter evoluído } \\
\text { no sentido da aprendizagem significativa. }\end{array}$ \\
\hline
\end{tabular}

Fonte: Dorneles (2010). 
Dorneles, P. F. T.; Araujo, I. S.; Veit, E. A.

Quadro 5. Resultados e classificação do Aluno 4

\begin{tabular}{|c|c|c|c|c|}
\hline \multicolumn{2}{|c|}{ Aluno 4} & \multirow{2}{*}{ 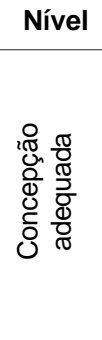 } & \multirow{2}{*}{\begin{tabular}{|l}
\multicolumn{1}{|c}{ Depoimento } \\
Serve como base para inícios de \\
experiências para saber como vai iniciar a \\
prática. Mas muitas vezes a teoria é bem \\
diferente da prática, pois na teoria existe \\
muitas vezes uma aproximação para que \\
os valores fiquem "elegantes". O modelo \\
teórico despreza alguns dados.
\end{tabular}} & \multirow[b]{2}{*}{\begin{tabular}{|l|}
\multicolumn{1}{|c|}{ Comentário interpretativo } \\
Esse aluno, também, apresentou argumentos \\
que sugerem que ele percebeu que os \\
modelos teóricos possuem idealizações e, \\
assim, um contexto de validade. Nas \\
questões dissertativas ele respondeu que o \\
progresso do conhecimento científico se dá \\
através de estudos teóricos e práticos, \\
hipóteses e modelos.
\end{tabular}} \\
\hline$\frac{\Im}{6}$ & 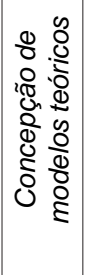 & & & \\
\hline & 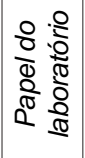 & 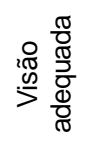 & $\begin{array}{l}\text { Poder comparar os resultados teóricos } \\
\text { com os práticos. Muitas vezes para se } \\
\text { chegar numa teoria e em outros casos } \\
\text { para verificar a teoria. }\end{array}$ & $\begin{array}{l}\text { Destacou as potencialidades do laboratório } \\
\text { em estabelecer um vínculo entre teoria e } \\
\text { realidade e de propiciar a exploração do } \\
\text { contexto de validade de modelos teóricos. }\end{array}$ \\
\hline$>$ & 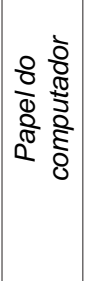 & 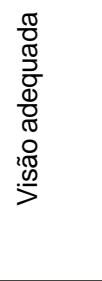 & $\begin{array}{l}\text { Dava para você visualizar bem ali no } \\
\text { computador, você variava o que tinha que } \\
\text { variar e percebia o que acontecia. }\end{array}$ & $\begin{array}{l}\text { Em relação ao computador, ele considerou } \\
\text { que é uma ferramenta que auxilia na } \\
\text { visualização. No entanto, também destacou } \\
\text { que, em algumas atividades, o computador } \\
\text { foi desnecessário. Segundo ele, nas aulas } \\
\text { sobre circuitos RL o uso do osciloscópio foi } \\
\text { suficiente para se atingirem os objetivos das } \\
\text { experiências. }\end{array}$ \\
\hline \multirow{3}{*}{ 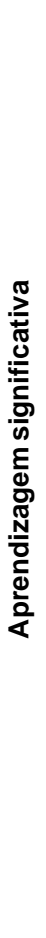 } & 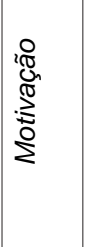 & 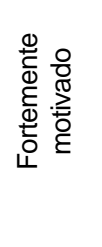 & $\begin{array}{l}\text { O laboratório talvez até desmotive } \\
\text { algumas pessoas porque às vezes vamos } \\
\text { para o laboratório sem conhecer o } \\
\text { assunto, então a experiência fica um } \\
\text { negócio mecanizado, sem entender o que } \\
\text { está acontecendo, preocupado só em } \\
\text { coletar dados para fazer o relatório. }\end{array}$ & $\begin{array}{l}\text { Na entrevista, ele destacou o vínculo entre } \\
\text { teoria e experimento como um elemento que } \\
\text { o motivou para o desenvolvimento das } \\
\text { atividades práticas. }\end{array}$ \\
\hline & 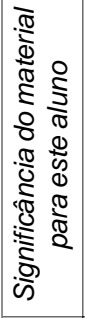 & : & $\begin{array}{l}\text { No princípio eu estava anotando o ângulo } \\
\text { porque cada vez que eu variava a } \\
\text { corrente o ângulo variava. Eu não sabia a } \\
\text { relação até o momento, depois que você } \\
\text { falou sobre as duas componentes aí é que } \\
\text { eu me liguei no significado do ângulo. }\end{array}$ & $\begin{array}{l}\text { Em quase todas as aulas, esse aluno } \\
\text { demonstrou ter interagido de maneira } \\
\text { significativa com os recursos instrucionais. } \\
\text { No entanto, em algumas aulas, mesmo já } \\
\text { tendo visto a parte teórica, ele começou a } \\
\text { interagir com os experimentos } \\
\text { mecanicamente, sem, inicialmente, refletir } \\
\text { sobre os procedimentos e pressupostos } \\
\text { teóricos envolvidos nas atividades. }\end{array}$ \\
\hline & 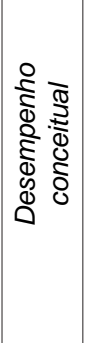 & $\frac{\frac{O}{c}}{\frac{c}{\Phi}}$ & $\begin{array}{l}\text { Se considerarmos } R_{L}>>r \text {, haverá uma } \\
\text { pequena variação no brilho da } L_{1} \\
\text { (diminuindo sua intensidade) ao fechar a } \\
\text { chave } A-B \text {.A potência aumenta } \\
\text { proporcionalmente com } R \text { até quando } R=r \text {, } \\
\text { assim a potência é máxima neste caso. A } \\
\text { potência dissipada em } R \text { e a dissipada na } \\
\text { fonte são iguais. Desconsidera a potência } \\
\text { dissipada na fonte quando } r<<R \text {. (Dado } \\
\text { complementar extraído dos guias) }\end{array}$ & $\begin{array}{l}\text { Esse aluno apresentou, na prova, uma } \\
\text { resposta correta, mas sem justificativa } \\
\text { convincente. Por isso, inserimos mais um } \\
\text { dado extraído do guia sobre uma simulação } \\
\text { de um circuito simples com uma fonte real, } \\
\text { em que ele demonstrou ter entendido } \\
\text { qualitativamente a influência da resistência } \\
\text { interna no circuito. Ao longo do semestre, ele } \\
\text { apresentou diversos indícios de ter evoluído } \\
\text { no sentido da aprendizagem significativa. }\end{array}$ \\
\hline
\end{tabular}

Fonte: Dorneles (2010). 
Integração entre atividades computacionais ...

Quadro 6. Resultados e classificação do Aluno 5

\begin{tabular}{|c|c|c|c|c|}
\hline \multicolumn{2}{|c|}{ Aluno 5} & \multirow{2}{*}{ 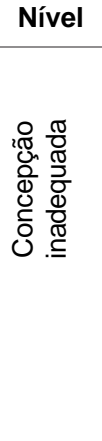 } & \multirow[b]{2}{*}{$\begin{array}{l}\text { Depoimento } \\
\text { O produto acabado da elaboração } \\
\text { intelectiva que consiste em observação, } \\
\text { hipótese, experimento e teoria. Este } \\
\text { modelo, quando testado por diversos } \\
\text { pesquisadores independentes e aceito por } \\
\text { grande parte do meio científico tornam-se } \\
\text { "leis", ou seja, a aplicação vigente para um } \\
\text { fenômeno em uma determinada época. }\end{array}$} & \multirow[b]{2}{*}{\begin{tabular}{l}
\multicolumn{1}{c}{ Comentário interpretativo } \\
No depoimento transcrito ao lado, esse aluno \\
apresentou indícios de uma visão empirista, \\
mas explicitou o caráter provisório dos \\
modelos científicos. Tanto no teste inicial \\
quanto no final, sobre a natureza da ciência \\
(Anexo D), ele novamente apresentou uma \\
visão empirista, concordando com as \\
afirmativas 4 e 8. Essa visão inadequada pode \\
estar impregnada de ideias sobre o \\
conhecimento científico do curso que ele fazia \\
paralelamente (Medicina).
\end{tabular}} \\
\hline & $\begin{array}{ll}0 & 0 \\
0 & 0 \\
0 & 0 \\
2 & 0 \\
0 & 0 \\
0 & 0 \\
0 & 0 \\
\delta & 0 \\
0 & 0 \\
0 & 0\end{array}$ & & & \\
\hline & 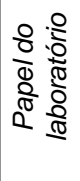 & 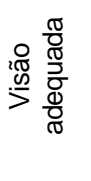 & $\begin{array}{l}\text { O ideal é o aluno escolher o que fazer para } \\
\text { desenvolver a cognição e a capacidade de } \\
\text { resolver problemas práticos de laboratório, } \\
\text { pois sempre dá um erro e tem que achar } \\
\text { uma solução. }\end{array}$ & $\begin{array}{l}\text { Classificou como uma atividade de laboratório } \\
\text { ideal a atividade em que escondemos, dentro } \\
\text { de uma caixa, as ligações de um circuito } \\
\text { elétrico e os alunos tiveram que inferir qual } \\
\text { tipo de associação tinha na caixa. }\end{array}$ \\
\hline & 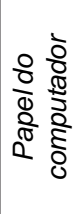 & & $\begin{array}{l}\text { A idealização dos fios e dos resistores não } \\
\text { estava diferenciando praticamente nada da } \\
\text { teoria com os valores apurados na prática } \\
\text { e só foi possível ver isso com uso do } \\
\text { computador para corrigir o nosso erro - era } \\
\text { um erro de cálculo. }\end{array}$ & $\begin{array}{l}\text { Esse aluno, em várias atividades, interagiu } \\
\text { com as simulações para verificar quanto as } \\
\text { idealizações adotadas nos modelos teóricos, } \\
\text { que orientam as medidas experimentais, } \\
\text { influenciam nos dados experimentais. }\end{array}$ \\
\hline \multirow{3}{*}{ 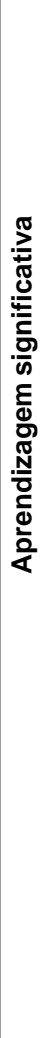 } & 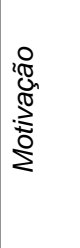 & 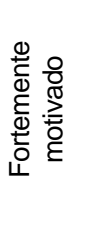 & $\begin{array}{l}\text { A presença de um projeto de pesquisa de } \\
\text { ensino, acaba aprimorando a qualidade } \\
\text { das aulas porque nunca vai ser deixado de } \\
\text { lado a parte didática; Às vezes em outras } \\
\text { disciplinas a parte didática é deixada de } \\
\text { lado e o professor cumpre a tarefa de } \\
\text { demonstrar teoremas pela matemática. }\end{array}$ & $\begin{array}{l}\text { Já na primeira aula ele se mostrou motivado } \\
\text { pela Física e não encontrou dificuldades para } \\
\text { desenvolver as atividades propostas, } \\
\text { apresentou um raciocínio rápido e coerente. }\end{array}$ \\
\hline & 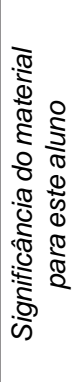 & 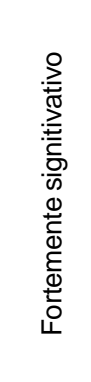 & $\begin{array}{l}\text { Eu acho bastante interessante [...] fazer a } \\
\text { atividade prática e depois, via o modelo } \\
\text { ideal, ver a diferença. Depois simular já } \\
\text { colocando a resistência interna no modelo } \\
\text { para ter três modelos: o real, o totalmente } \\
\text { idealizado e o idealizado com nível de } \\
\text { realidade que é a resistência interna da } \\
\text { fonte, daí pode se observar o quanto da } \\
\text { diferença entre o real e o idealizado se } \\
\text { deve a resistência interna e quanto se } \\
\text { deve a outros fatores. }\end{array}$ & $\begin{array}{l}\text { Nas aulas, este aluno fazia perguntas que } \\
\text { mostravam que estava acompanhando o que } \\
\text { era proposto nos guias. Não se satisfazia com } \\
\text { qualquer resposta. Em muitos casos, era } \\
\text { necessário apresentar exemplos para } \\
\text { convencê-lo sobre os significados dos } \\
\text { conceitos e das relações entre grandezas } \\
\text { físicas envolvidas nas atividades. }\end{array}$ \\
\hline & 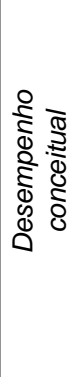 & 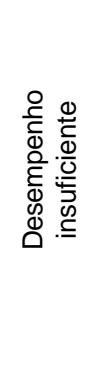 & $\begin{array}{l}\text { Diminui, ao fechar A-B produz um circuito } \\
\text { em paralelo com uma resistência elétrica } \\
\text { menor que a original. Isto aumenta a } \\
\text { energia dissipada pela resistência interna. } \\
\text { Caso na bateria não houvesse resistência } \\
\text { a associação de outra lâmpada diminuiria a } \\
\text { resistência equivalente pela metade } \\
\text { dobrando a corrente, que se dividiria entre } \\
\text { as lâmpadas igualmente, mantendo a } \\
\text { mesma corrente em } L_{1} \text {, que manteria seu } \\
\text { mesmo brilho. }\end{array}$ & $\begin{array}{l}\text { Ao longo do semestre, esse aluno sempre } \\
\text { buscou apresentar respostas com } \\
\text { argumentação física, apresentando elementos } \\
\text { que mostram que foi capaz de relacionar, de } \\
\text { forma significativa, os conceitos físicos } \\
\text { envolvidos nas atividades com suas ideias e } \\
\text { conceitos prévios. Observa-se que esse aluno } \\
\text { percebeu o significado do conceito de } \\
\text { resistência elétrica. }\end{array}$ \\
\hline
\end{tabular}

Fonte: Dorneles (2010). 
Dorneles, P. F. T.; Araujo, I. S.; Veit, E. A.

Quadro 7. Resultados e classificação do Aluno 6

\begin{tabular}{|c|c|c|c|c|}
\hline \multicolumn{2}{|c|}{ Aluno 6} & \multirow{2}{*}{ 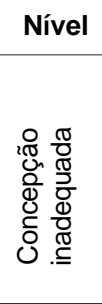 } & \multirow{2}{*}{\begin{tabular}{|l|}
\multicolumn{1}{|c|}{ Depoimento } \\
A força deve diminuir ao aumentarmos a \\
distância, porém existe um erro na \\
programação do Modellus. Existia um \\
termo a mais multiplicando a equação \\
de $B_{3}$.
\end{tabular}} & \multirow{2}{*}{\begin{tabular}{l}
\multicolumn{1}{c}{ Comentário interpretativo } \\
Esse aluno apresentou indícios de ter refletido \\
sobre o domínio de validade dos modelos \\
teóricos. Em uma atividade em que inserimos \\
propositalmente um erro, ele foi um dos \\
primeiros alunos a perceber que tinha algo de \\
errado no modelo teórico subjacente à \\
implementação da simulação computacional.
\end{tabular}} \\
\hline \multirow{3}{*}{ 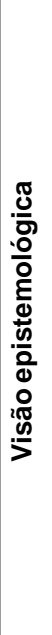 } & $\begin{array}{ll}0 & 0 \\
0 & 0 \\
0 & 0 \\
0 & 0 \\
0 & 0 \\
0 & 0 \\
0 & 0 \\
0 & 0 \\
0 & 0 \\
0 & 0\end{array}$ & & & \\
\hline & 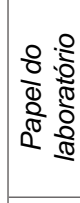 & 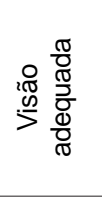 & $\begin{array}{l}\text { Eu aprendi muito, a gente montava o } \\
\text { circuito e tinha o osciloscópio aquilo foi } \\
\text { muito bom, mais que o computador [...]o } \\
\text { osciloscópio ta ligado diretamente ao } \\
\text { circuito. Entre a teoria e o experimento. }\end{array}$ & $\begin{array}{l}\text { semestre, apres } \\
\text { de manipulação } \\
\text { propiciando uma } \\
\text { procedimentos } p \\
\text { preencher os gu }\end{array}$ \\
\hline & 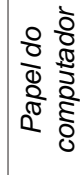 & 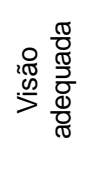 & $\begin{array}{l}\text { O computador ajuda a entender como as } \\
\text { coisas funcionam no experimento, a } \\
\text { visualização. }\end{array}$ & $\begin{array}{l}\text { Apesar disso, de forma semelhante ao Aluno } 3 \text {, } \\
\text { ele comentou, na entrevista, que, em algumas } \\
\text { atividades, preferiu interagir somente com o } \\
\text { osciloscópio, pois as curvas apresentadas foram } \\
\text { suficientes para desenvolverem as atividades. }\end{array}$ \\
\hline \multirow{3}{*}{ 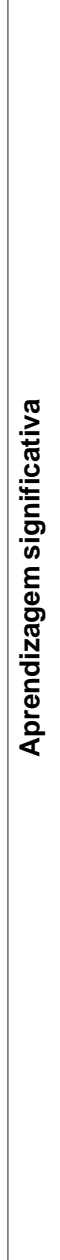 } & 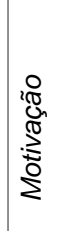 & 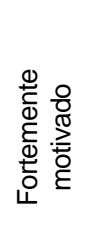 & $\begin{array}{l}\text { O trabalho em grupo e a interação com } \\
\text { os professores juntos formam uma coisa } \\
\text { forte, não sei dizer qual seria o mais } \\
\text { importante. Até comentamos quando } \\
\text { estávamos indo embora que a gente } \\
\text { anda pensando muito, esse trabalho é } \\
\text { diferente, faz a gente, pensar. }\end{array}$ & $\begin{array}{l}\text { ou motivado para } \\
\text { teragir com os } \\
\text { te, suas dúvidas eram } \\
\text { a partir das reflexões } \\
\text { explicitar os } \\
\text { e, assim, encontrar as } \\
\text { as. }\end{array}$ \\
\hline & 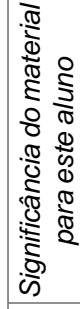 & 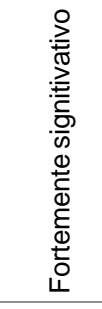 & $\begin{array}{l}\text { A maior dificuldade que encontrei foi o } \\
\text { uso do computador, pois sempre que eu } \\
\text { colocava alguma coisa o computador } \\
\text { mostrava outra, depois estudei mais } \\
\text { porque deu tudo errado aí fiquei mais } \\
\text { motivado. É bom a gente não ter visão } \\
\text { errada. É bem esclarecedor. }\end{array}$ & $\begin{array}{l}\text { Essa dificuldade apresentada inicialmente pelo } \\
\text { aluno não evidencia uma dificuldade de interação } \\
\text { com o computador, e sim divergências entre o } \\
\text { que ele esperaria que o computador mostrasse e } \\
\text { o que realmente era mostrado. Também, } \\
\text { evidencia a potencialidade de os guias propostos } \\
\text { com base no método PIE propiciarem uma } \\
\text { reflexão dos alunos sobre suas próprias } \\
\text { concepções. }\end{array}$ \\
\hline & 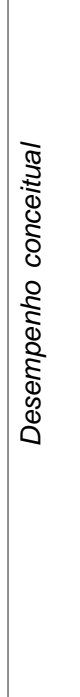 & 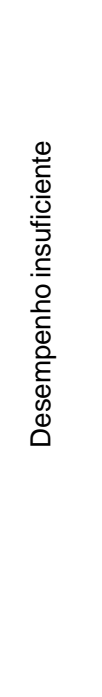 & $\begin{array}{l}\text { Nesta situação o brilho de } L_{1} \text { diminui, } \\
\text { pois a corrente que passava inteira em } \\
L_{1} \text { agora se divide em duas para } \\
\text { acender, também } L_{2} \text {.S Sabemos que } \\
\text { quando a potência é máxima, a } \\
\text { resistência interna ré igual a resistência } \\
\text { externa } R \text {. Realizamos medidas de } R \text { e } \\
\text { da corrente para obtermos um gráfico da } \\
\text { potência versus } R \text {. O valor máximo da } \\
\text { potencia está relacionado com um valor } \\
\text { de } R \text { que é igual a r e assim } \\
\text { encontramos um valor para r dentro da } \\
\text { margem de erro. (Dado complementar } \\
\text { extraído dos guias) [...] insatisfeitos com } \\
\text { o primeiro gráfico que plotamos (devido a } \\
\text { erros grosseiros), refizemos nossas } \\
\text { medidas e obtivemos resultados } \\
\text { satisfatórios, pois a curva saiu como } \\
\text { esperávamos e encontra-se dentro das } \\
\text { barras de erros. (Dado extraído da } \\
\text { análise individual sobre dados } \\
\text { experimentais) }\end{array}$ & $\begin{array}{l}\text { A resposta inicial evidencia uma concepção } \\
\text { alternativa de que uma bateria é uma fonte de } \\
\text { corrente contínua. No entanto, o seu grupo foi } \\
\text { capaz de explicar os procedimentos realizados } \\
\text { para encontrarem, experimentalmente, a } \\
\text { resistência interna de uma fonte. Nessa aula, } \\
\text { eles encontraram alguns dados experimentais } \\
\text { que não estavam de acordo com o esperado. } \\
\text { Então, solicitamos que refizessem as medidas e } \\
\text { realizassem em casa, individualmente, uma } \\
\text { análise sobre a confiabilidade dos dados } \\
\text { experimentais. A argumentação transcrita ao lado } \\
\text { evidencia que ele trabalhou ativamente, e não } \\
\text { simplesmente acompanhou os raciocínios e } \\
\text { procedimentos do seu colega. Nos demais } \\
\text { dados, ele demonstrou ter captado os } \\
\text { significados dos conceitos presentes nas } \\
\text { atividades, e não apresentou mais concepções } \\
\text { alternativas. }\end{array}$ \\
\hline
\end{tabular}

Fonte: Dorneles (2010). 
Ainda em relação à proposição 1, aprofundamos a análise dos dados quantitativos apresentados na Figura 3 (a) destacando que o escore baixo na afirmativa 8, no pós-teste, se deve ao fraco desempenho dos alunos 1, 3, 4 e 5. Destes, apenas o Aluno 5 apresentou, nas questões dissertativas respondidas ao final do semestre (Apêndice B), claras evidências de ter persistido com uma visão empirista-indutivista, conforme descrito na primeira linha do Quadro 6. Conforme pode-se ver na Figura 3 (b), os alunos 3 e 4 foram os que obtiveram menor escore no pós-teste, e, em nossas observações, percebemos que trabalharam em muitas aulas de forma mecânica, o que pode ter dificultado que captassem um dos objetivos de nossa proposta didática, que é o de possibilitar uma visão de que a ciência contemporânea não é apenas experimentação, e sim teoria mais experiência. Porém, esses alunos não explicitaram, nos dados qualitativos, qualquer indício empirista-indutivista. O Aluno 1 também não apresentou uma visão empirista-indutivista nos demais dados, e a afirmativa 8 foi a única em que ele se posicionou de forma equivocada, na nossa concepção. O desempenho dos alunos no pós-teste, comparado ao do pré-teste, e suas manifestações na entrevista final, comparadas às suas respostas às questões dissertativas respondidas na primeira aula, nos levam a considerar que a proposta didática adotada se mostrou capaz de auxiliar os alunos a terem uma visão mais adequada sobre a natureza da Ciência.

Quanto à proposição 2, que diz respeito à transformação das aulas de Física em um ambiente propício para a aprendizagem significativa, podemos dizer que:

- em relação à motivação: todos os alunos atingiram o nível máximo na escala de medida, inclusive o Aluno 3, que não apresentou, de forma espontânea na entrevista, argumentos positivos sobre nossa metodologia didática, mas durante o desenvolvimento das atividades interagiu fortemente com seus colegas. Em algumas aulas, não somente ele interagiu com seu colega de grupo, mas, com dúvidas, procurou algum outro grupo para discutir suas dificuldades. Outro dado importante sobre a predisposição dos alunos para aprender é que, com frequência, eles continuavam de forma espontânea trabalhando nas atividades após o horário de término da aula;

- a respeito da significância do material instrucional para os alunos, observamos que os guias preenchidos em grupo, em sua ampla maioria, mostram respostas corretas e com boa argumentação física, no entanto, esses dados podem também ser atribuídos ao auxílio dos professores, pois, como tínhamos poucos grupos (três), identificávamos sistematicamente erros dos alunos, durante as aulas, e os auxiliávamos a corrigi-los. Por isso, também, buscamos outras fontes de dados (entrevista semiestruturada e gravações enquanto os alunos trabalhavam) com o objetivo de avaliar os procedimentos e opinião dos alunos sobre o material. Os dados sugerem que apenas o Aluno 4 não foi capaz de relacionar, de maneira não arbitrária e não literal, o conteúdo presente nos materiais com suas ideias prévias, em várias aulas. Os demais alunos apresentaram depoimentos de que foram capazes de relacionar satisfatoriamente os procedimentos e raciocínios desenvolvidos durante as aulas com elementos de sua estrutura cognitiva;

. em relação ao desempenho conceitual dos alunos com base nos dados qualitativos, encontramos indícios que nos levam a considerar que os alunos 1, 2, 3, 5 e 6 atingiram um desempenho bom. O Aluno 4 apresentou um rendimento insuficiente tanto para suprir nossas expectativas quanto para ser aprovado na disciplina. Esse aluno foi o que, em várias aulas, não foi capaz de perceber a significância do material instrucional e, assim, trabalhou de forma 
mecanizada. Isso sugere que apenas o Aluno 4 não evoluiu para uma aprendizagem significativa dos conceitos físicos envolvidos no ensino de Eletromagnetismo, pois nossas avaliações foram formuladas de maneira nova e não familiar, requerendo alguma transformação do conhecimento adquirido, tal como propõe Ausubel (2003).

Em síntese, encontramos fortes indícios de que as proposições 1 e 2 foram corroboradas no presente estudo, pois as medidas de motivação, significância do material e papel do computador se situaram em um nível elevado; desempenho conceitual e papel do laboratório em um nível bom, exceto no caso de um aluno; e concepção de modelo teórico, também em um nível bom, exceto no caso de um outro aluno.

\section{Considerações finais}

Com o presente trabalho, concluímos a apresentação de resultados de uma série de estudos em que buscamos conceber, implementar e avaliar uma proposta didática sobre o ensino de Eletromagnetismo. Em todos os estudos, levamos em conta as dificuldades de aprendizagem relatadas na literatura, buscando auxiliar os alunos a superá-las e propiciar melhores condições para uma aprendizagem significativa na acepção de Ausubel (2003; MOREIRA, 2006). Também buscamos estabelecer uma dinâmica de sala de aula capaz de promover a interação social defendida por Vygotsky (2003) como meio para a aprendizagem. No presente estudo, passamos a ter como meta, também, a possibilidade de propiciar aos alunos uma visão epistemológica sobre os papéis do laboratório didático de Física e de modelos teóricos na acepção de Bunge (1994). Utilizando esses referenciais teóricos, fundamentamos uma proposta de integração entre atividades experimentais e computacionais, e realizamos uma experiência didática que teve a duração de 25 aulas (totalizando 68 horas-aula). Os resultados mostram que a integração entre esses dois tipos de atividades pode proporcionar, aos alunos, uma visão epistemológica mais adequada sobre os papéis dos modelos teóricos, do laboratório e do computador, e promover a interatividade e o engajamento dos alunos em seu próprio aprendizado, transformando a sala de aula em um ambiente propício para uma aprendizagem significativa dos conceitos físicos de Eletromagnetismo em nível de Física Geral.

A título de conclusão, destacamos que observamos uma evolução nas respostas dos alunos ao longo do semestre, sobretudo nas atividades em que usaram o computador e o material experimental simultaneamente, provavelmente porque os guias que os orientavam nessas atividades estavam repletos de questionamentos. Os alunos deixaram de dar respostas lacônicas, passando a justificar suas respostas com alguma argumentação conceitual, ainda que, por vezes, as empregassem de modo errôneo. Observamos, também, que não há necessidade de que o computador esteja presente em todas as atividades experimentais, mas uma metodologia didática como o método Prediz̨er, interagir e explicar é indispensável para tornar os alunos mais críticos nas aulas de laboratório. Isso está de acordo com os resultados de Crouch et al. (2004), que sugerem que, com o simples uso de atividades de demonstração, os alunos aprendem pouco, mas quando solicitados a fazerem algumas predições antes de verem a demonstração, podem apresentar melhor compreensão dos conceitos físicos envolvidos. Se além das predições lhes for propiciada a oportunidade de discussão, a compreensão é ainda maior. Outro aspecto importante que deve estar presente em todas as aulas de laboratório é a expli- 
Integração entre atividades computacionais ...

citação do vínculo entre teoria e experimento, para que o aluno se torne motivado e interaja de forma significativa com os experimentos. Em relação às atividades computacionais, depois que os alunos exploraram uma simulação em que propositadamente havíamos introduzindo um "erro", sem alertá-los, eles se tornaram mais críticos e reflexivos quanto aos modelos que regem as simulações, deixando de considerá-las inquestionavelmente certas.

\section{Agradecimentos}

Agradecemos ao Prof. Dr. Marco Antonio Moreira, que coorientou o doutorado do primeiro autor, e aos árbitros, pelas críticas pertinentes, que promoveram melhorias no trabalho.

\section{Referências}

ARAUJO, I. S.; VEIT, E. A. Uma revisão da literatura sobre estudos relativos a tecnologias computacionais no ensino de física. Revista Brasileira de Pesquisa em Educação em Ciências, Belo Horizonte, v. 4, n. 3, p. 5-18, 2004.

ARAUJO, I. S.; VEIT, E. A.; MOREIRA, M. A. Physics students' performance using computational modelling activities to improve kinematics graphs interpretation. Computers \& Education, New York, v. 50, n. 4, p.1128-1140, 2008.

AUSUBEL, D. P. Aquisição e retenção de conhecimentos: uma perspectiva cognitiva. Lisboa: Plátano, 2003.

BORGES, A. T. Novos rumos para o laboratório escolar de ciências. Caderno Brasileiro de Ensino de Física, Florianópolis, v. 19, n. 3, p. 803-815, 2002.

BUNGE, M. Teoria e realidade. São Paulo: Perspectiva, 1974.

CROUCH, C. H. et al. Classroom demonstrations: learning tools or entertainment? American Journal of Physics, New York, v. 72, n. 6, p. 835-838, 2004.

DORNELES, P. F. T. Integração entre atividades computacionais e experimentais como recurso instrucional no ensino de eletromagnetismo em física geral. 2010. 367 f. Tese (Doutorado em Ciências) - Instituto de Física, Universidade Federal do Rio Grande do Sul, Porto Alegre, 2010.

DORNELES, P. F. T.; ARAUJO, I. S.; VEIT, E. A. A integração entre atividades computacionais e experimentais: um estudo exploratório no ensino de circuitos cc e ca em física geral. In: ENCONTRO NACIONAL DE PESQUISA EM EDUCAÇÃO EM CIÊNCIAS, 6., 2007. Atas... Florianópolis: ABRAPEC, 2007. v. 1.

DORNELES, P. F. T.; VEIT, E. A.; MOREIRA, M. A. Investigating the learning of RLC circuits with the aid of computer-based. In: GIREP 2008 INTERNATIONAL CONFERENCE: PHYSICS CURRICULUM DESIGN, DEVELOPMENT AND VALIDATION, 2008, Nicosia, Chipre. Proceedings.... S.l.: Girep, 2008. v. 1. p. 1-13. 
Dorneles, P. F. T.; Araujo, I. S.; Veit, E. A.

DORNELES, P. F. T.; VEIT, E. A.; MOREIRA, M. A. A study about the learning of students who worked with computational modeling and simulation in the study of simple electric circuits. Revista Electrónica de Enseñanza de las Ciencias, v. 9, n. 3, p. 569-595, 2010.

DORNELES, P. F. T.; VEIT, E.; ARAUJO, I. S. Atividades experimentais e computacionais como recursos instrucionais que se complementam: um estudo exploratório no ensino de eletromagnetismo em física geral. Enseñanza de las Ciencias, Barcelona, p. 1806-1810, 2009. (Número Extra). Disponível em: <http://ensciencias.uab.es/congreso09/ numeroextra/art-1806-1810.pdf>. Acesso em: 26 nov 2009.

FINKELSTEIN, N. D. et al. When learning about the real world is better done virtually: a study of substituting computer simulations for laboratory equipment. Physical Review Special Topics-Physics Education Research, College Park, v. 1, n. 1, p.010103-1010103-8, 2005.

GIL-PÉREZ, D. et al. ¿'Tiene sentido seguir distinguiendo entre aprendizaje de conceptos, resolución de problemas de lápiz y papel y realización de práticas de laboratorio?

Enseñanza de las Ciencias, Barcelona, v. 12, n. 2, p. 311-320, 1999.

HALLIDAY, D.; RESNICK, R.; WALKER, J. Fundamentos de física. 6. ed. Rio de Janeiro: LTC, 2003. v. 3.

HENNESSY, S.; DEANEY, R.; RUTHVEN, K. Situated expertise in integrating use of multimedia simulation into secondary Science Teaching. International Journal of Science Education, London, v. 28, n. 7, p. 701-732, 2006.

HODSON, D. Hacia un enfoque más crítico del trabajo de laboratorio. Enseñanza de las Ciencias, Barcelona, v. 12, n. 3, p. 299-313, 1994.

JAAKKOLA, T.; NURMI, S. Fostering elementary school students'understanding of simple electricity by combining simulation and laboratory activities. Journal of Computer Assisted Learning, Oxford, v. 24, n. 4, p. 271-283, 2008.

MARINELI, F; PACCA, J. L. A. Uma interpretação para dificuldades enfrentadas pelos alunos em um laboratório didático de Física. Revista Brasileira de Ensino de Física, São Paulo, v. 28, n. 4, p. 497-505, 2006.

MEDEIROS, A.; MEDEIROS, C. F. D. Possibilidades e limitações das simulações computacionais no ensino da física. Revista Brasileira de Ensino de Física, São Paulo, v. 24, n. 2, p. 77-86, 2002.

MOREIRA, M. A. A teoria da aprendizagem significativa e sua implementação em sala de aula. Brasília: Editora Universidade de Brasília, 2006.

. Teorias de aprendizagem. São Paulo: E.P.U, 1999.

RONEN, M.; ELIAHU, E. Simulation - a bridge between theory and reality: the case of electric circuits. Journal of Computer Assisted Learning, Oxford, v. 16, n. 1, p. 14-26, 2000. 
Integração entre atividades computacionais ...

RUIZ C. et al. Construcción de mapas cognitivos a partir del cuestionario INPECIP. Aplicación al estudio de la evolución de las concepciones de una profesora de secundaria entre 1993 y 2002. Revista Electrónica de Enseñanza de las Ciencias, v. 4, n. 1, 2005.

STEINBERG, R. N. Computers in teaching science: to simulate or not to simulate? American Journal of Physics, New York, v. 68, n. 7, p. S37-S41, 2000. (Supplement).

TAO, P.-K.; GUNSTONE, R. F. The process of conceptual change in force and motion during computer-supported physics instruction. Journal of Research in Science Teaching, New York, v. 36, n. 7, p. 859-882, 1999.

VYGOTSKY, L. S. A construção do pensamento e da linguagem. São Paulo: Martins Fontes. 2001.

Pensamento e linguagem. São Paulo: Martins Fontes, 2003.

YIN, R. K. Estudo de caso: planejamento e métodos. Porto Alegre: Bookman, 2005.

ZACHARIA, Z. C. Comparing and combining real and virtual experimentation: an effort to enhance students' conceptual understanding of electric circuits. Journal of Computer Assisted Learning, Oxford, v. 23, n. 2, p. 83-169, 2007.

ZACHARIA, Z. C.; ANDERSON, R. The effects of an interactive computer-based simulation prior to performing a laboratory inquiry-based experiment on students' conceptual understanding of physics. American Journal of Physics, New York, v. 71, n. 6, p. 519-640, 2003.

ZACHARIA, Z. C.; CONSTANTINOU, C. P. Comparing the influence of physical and virtual manipulatives in the context of the Physics by Inquiry curriculum: The case of undergraduate students' conceptual understanding of heat and temperature. American Journal of Physics, Melville, v. 76, n. 4/5, p. 425-430, 2008.

ZACHARIA, C. Z.; OLYMPIOU, G.; PAPAEVRIPIDOU, M. Effects of Experimenting with physical and virtual manipulatives on students' conceptual understanding in heat and temperature. Journal of Research in Science Teaching, New York, v. 45, n. 9, p. 1021 1035, 2008. 
Dorneles, P. F. T.; Araujo, I. S.; Veit, E. A.

APÊNDICE A - Questões dissertativas respondidas pelos alunos no primeiro dia de aula.

1) Como se dá o progresso do conhecimento científico?

2) Qual o papel da experimentação em Física?

APÊNDICE B - Entrevista semiestruturada realizada durante o desenvolvimento do estudo (aula 16).

1) Considere os seguintes fatores: (a) uso de experimentos; (b) uso do computador; (c) trabalho em grupo; (d) interação com o professor. Ordene do mais importante ao menos importante para:

\begin{tabular}{|c|c|c|c|}
\hline . o seu aprendizado & $1^{\circ}()$ & $2^{\circ}()$ & $3^{\circ}()$ \\
\hline . a sua motivação para aprender & $1^{\circ}()$ & $2^{\circ}()$ & $3^{\circ}()$ \\
\hline . as suas dificuldades & $1^{\circ}()$ & $2^{\circ}()$ & $3^{\circ}()$ \\
\hline
\end{tabular}

2) Comente um pouco sobre a integração entre as atividades experimentais e computacionais.

3) Qual sua opinião sobre atividades que exploram as diferenças entre um sistema real e um sistema ideal?

APÊNDICE C - Questões dissertativas respondidas pelos alunos no último dia de aula.

1) Como se dá o progresso do conhecimento científico?

2) Qual o papel do laboratório didático em Física?

3) Qual o papel de modelos teóricos?

4) Qual o papel do uso do computador em Física?

Artigo recebido em 26/01/2011. Aceito em 09/08/2011.

Ciência \&̊̊ Educação, v. 18, n. 1, p. 99-122, 2012 